This PDF is a selection from an out-of-print volume from the National Bureau of Economic Research

Volume Title: Frontiers in Health Policy Research, Volume 3

Volume Author/Editor: Alan M. Garber, editor

Volume Publisher: MIT Press

Volume ISBN: 0-262-57141-2

Volume URL: http://www.nber.org/books/garb00-1

Publication Date: January 2000

Chapter Title: Why Do Some Firms Spend So Much on Medical Care? Accounting for Variation

Chapter Author: Matthew Eichner, Mark McClellan, David A. Wise

Chapter URL: http://www.nber.org/chapters/c9828

Chapter pages in book: (p. 1 - 32) 


\title{
Why Do Some Firms Spend So Much on Medical Care? Accounting for Variation
}

\author{
Matthew Eichner, Columbia University \\ Mark McClellan, Stanford University and NBER \\ David A. Wise, Harvard University and NBER
}

\section{Executive Summary}

We are engaged in a long-term project to analyze the determinants of health care cost differences across firms. An important first step is to summarize the nature of expenditure differences across plans. The goal of this article is to develop methods for identifying and quantifying those factors that account for the wide differences in health care expenditures observed across plans.

We consider eight plans that vary in average expenditure for individuals filing claims, from a low of $\$ 1,645$ to a high of $\$ 2,484$. We present a statistically consistent method for decomposing the cost differences across plans into component parts based on demographic characteristics of plan participants, the mix of diagnoses for which participants are treated, and the cost of treatment for particular diagnoses. The goal is to quantify the contribution of each of these components to the difference between average cost and the cost in a given firm. The demographic mix of plan enrollees accounts for wide differences in cost (\$649). Perhaps the most noticeable feature of the results is that, after adjusting for demographic mix, the difference in expenditures accounted for by the treatment costs given diagnosis (\$807) is almost as wide as the unadjusted range in expenditures ( $\$ 838$ ). Differences in cost due to the different illnesses that are treated, after adjusting for demographic mix, also accounts for large differences in cost (\$626). These components of cost do not move together; for example, demographic mix may decrease expenditure under a particular plan while the diagnosis mix may increase costs.

Our hope is that understanding the reasons for cost differences across plans will direct more focused attention to controlling costs. Indeed, this work is intended as an important first step toward that goal.

Almost two-thirds of Americans under sixty-five are covered by employer insurance plans. Like the costs of Medicare coverage for elderly Americans, employer medical costs have risen rapidly in the past several decades. For part of the 1990s, this growth slowed with the adoption of a broad range of managed-care methods and other steps to 
control costs. But recent reports indicate that, despite these reforms, private insurance costs are rising again.

Through the 1990s, research on the consequences of cost control efforts in private insurance plans has been limited. Unlike the uniform national provisions of the fee-for-service Medicare system, the provisions of employer plans vary greatly from firm to firm, as do the costs of medical care, suggesting that differences in plan provisions may have a substantial effect on health care expenditures. Thus, analysis of employer plans provides a unique opportunity to understand the relationship between plan provisions and expenditures for health care.

The mechanisms that might be effective in controlling cost, however, will depend on the source of cost differences. For example, if cost differences are accounted for mostly by a small number of plan enrollees who are treated for specific high-cost illnesses, efforts to control cost must necessarily focus on the treatment of these illness. If cost differences are due to variation in the use of intensive procedures, then it is important to know what these procedures are and what types of patients are treated differently. In contrast, if cost differences result from more modest differences in the expenditures incurred by a large number of enrollees, then effective cost-control mechanisms would have to be directed toward the medical utilization of more typical enrollees, for example, those who use only outpatient services.

In this article we focus not on the incentive effects of plan provisions-whether demand-side price incentives or supply-side limits on care-but on the sources of cost differences across plans. We are engaged in a long-term project to analyze the determinants of cost differences across firms. In particular, we look forward to empirical analysis that can be used to predict the effect on medical expenditures of specific changes in medical insurance plan provisions. The project is based on insurance claims records from a large number of employers. The vast amount of information on insurance claims records is both a blessing and a curse. A key advantage of claims data is the amount of detail they provide. They provide enormous opportunity to study the nature of treatments and expenditures in employer-provided plans, but they also present a substantial analytic challenge.

We began work in this area by describing where the money goes in a single large firm (McClellan and Wise 1995). We have also used the panel nature of the data to direct attention to the relationship between individual health care expenditures over time, focusing on the implications of persistence for the feasibility of medical saving accounts 
(Eichner, McClellan, and Wise 1997, 1998). But the analysis dealt only with expenditure over time in a single firm. Eichner (1997) considered the incentive effects of the provisions of a menu of plans, again within a single firm.

An important first step in comparing expenditure across many plans is to summarize the nature of expenditure differences across plans, which is attempted in this article. In particular, the goal is to understand what accounts for the wide differences in health care expenditures across plans. We present a statistically consistent method for decomposing expenditures, thus providing an understanding of the sources of differences across firms. While this method is perhaps the most important focus of the article, the substantive results are also of interest. Our hope is that understanding the reasons for cost differences across plans will direct more focused attention to analysis of the ways that costs can be controlled. Indeed, this work is intended as an important first step toward that goal.

We consider eight plans that vary in average expenditure for individuals filing claims, from a low of $\$ 1,645$ to a high of $\$ 2,484$. We then propose a method to decompose these differences into their component parts. The goal is to quantify the contribution of each component to total cost variation across firms. We believe that this method allows us to point directly to the sources of cost differences and thus help us to focus subsequent analysis where it is most likely to make a difference. This general analysis of cost variation across plans can then provide the basis for additional studies of the effects of plan provisions on costs.

Identifying the effect of plan provisions on health care costs is complicated for several reasons. Differences in plan costs may be caused by many factors other than plan incentive effects, including geographic location and the demographic attributes of plan members. Much more difficult to account for are unobserved differences in the types of individuals selecting health plans; individuals who expect to use more health care, who are more risk averse, or who possess a "taste" for health care are more likely to choose more generous plans when an employer offers a menu of plans. Eichner (1997) has devoted a great deal of attention to this issue. And we will return to it once the sources of cost differences are understood better.

Our work using large longitudinal data sets on firm employees and their dependents is in some ways analogous to studies using large longitudinal Medicare claims databases. An extensive research literature has documented large variations in treatment rates and intensity for 
many illnesses in the elderly, leading to enormous variations in costs across groups of beneficiaries based on geographic residence and many other characteristics. All beneficiaries in the traditional Medicare program are subject to essentially the same health plan characteristics. But Medicare data have been used to document that many other policyrelevant factors, including state laws, competition, managed care pressures, socioeconomic status, and technology availability, can significantly influence Medicare costs and possibly patient outcomes through various mechanisms.

Our research represents a first effort to use detailed medical claims data from large firms to understand the sources and causes of medical expenditure differences across firms. Previous studies of private health insurance have focused almost entirely on firm surveys, population surveys, or hospital discharge databases, none of which are adequate to obtain a comprehensive understanding of health care spending by private plans. Records from individual insurers have been used to describe the major components of health care spending. But these studies typically involve a pool of records for covered individuals of many employers and thus are based on diverse financial incentives to use services and may not represent an entire firm population. Detailed firm data have also been used in a few studies to provide evidence on differences in the cause of treatment for some conditions. To our knowledge, the evidence we present here is the first detailed decomposition of the sources of cost differences across health plans.

We consider both the rate of treatment and the treatment cost given treatment for thirty diagnostic groups. We first consider how much of the rate and the cost for each treatment can be attributed to the demographic mix of plan members. The total demographic effect is divided between the effect of demographic mix on the rate of diagnoses and on the effect on treatment cost given diagnosis. The cost differences that remain after the demographic adjustment, are also divided between rate and treatment effects.

Previous descriptive studies have documented cost differences associated with firm location and employee demographic characteristics, based largely on aggregate cost differences. Whether cost variation across plans is due to more intensive treatment of a few high-cost enrollees or to marginally more intensive treatment for the majority of plan enrollees is unknown. We believe that understanding where the intensity, and hence cost, of treatment differs will be the basis for additional analysis of the effects of plan provisions on costs. 
Detailed descriptive analyses may also provide evidence on how cost differences due to selection effects arise within plans. Understanding both the incentives of plan provisions and the effects of choosing a plan may be enhanced by analysis aimed at identifying the kind of patients and medical treatments that contribute most to cost differences. For example, a larger proportion of patients with heart disease or other chronic illness enrolling in one plan out of a menu of plans from which employees can choose may well reflect selection effects. On the other hand, higher costs due to acute conditions that can be treated in very different ways, such as a back injury or heart attack, may reflect plan provision (incentive) effects. Similarly, higher costs due to more intensive treatment given the occurrence of an illness may represent plan incentive effects as these affect patients, providers, or both. Describing the sources of cost differences at this level of detail not only provides some evidence about whether cost differences are due to selection or incentive effects but also provides a detailed foundation for more explicit causal studies of how plan provisions affect expenditures. For example, studies of changes in incidence or intensity of particular health problems resulting from reforms in health plan structure are likely to provide insight into how particular plan provisions affect expenditures.

We address many but not all of these questions by analyzing cost differences in insurance plans offered by eight firms. We first describe the claims data used for the analysis and present summary information on medical expenditures in the selected firms. We then describe the decomposition method used to determine the sources of cost differences among these eight firms. Calculations based on this method are then presented in graphs. The last section is a summary and discussion.

\section{The Data and Summary Description}

\section{The Data}

The analysis is based on a unique data set obtained from MedStat/ Systemetrics. The data provide comprehensive information on medical utilization for enrollees in various employer-provided health insurance regimes. The data include all inpatient and outpatient health insurance claims filed by employees and their dependents in forty-five firms that self-insure; that is, these firms may pay an insurance carrier to process claims and help control costs but not to assume financial risk. All risk is 
borne by the employer, who essentially pays the annual medical bills of its employees and their dependents. The firms are drawn from several industries and reflect a range of health care cost experiences, plan provisions, and workforce characteristics.

The data content is standardized through an ongoing process with MedStat designed to provide essentially identical data for each firm. Each claim includes a patient identifier, a provider identifier, the date of the medical service, the claim amount, the co-payment and deductible amounts paid by the patient, the place of service- hospital, physician office, intermediate care facility, etc.-and ICD-9 and CPT- 4 codes identifying the principal diagnoses and procedures performed. While we expect that our procedure coding is generally accurate (they influence billing in our participating plans), several studies have documented the limited reliability of particular diagnosis codes, especially in the outpatient setting. For this reason, in the principal analysis reported here, we group patients who receive outpatient-only treatment into a single residual category and focus our disease-specific analysis on patients who receive some inpatient treatment. (We report the cost for inpatient versus outpatient analysis for mental health and substance abuse care in some illustrative additional analysis at the end of the article.) We also focus on a patient's predominant diagnosis (defined below) to minimize the impact of specific erroneously reported claims. The patient's age, sex, relationship to the employee, and employment status-hourly or salaried, active or retired-are also reported in our data.

The primary goal of this article is to illustrate our decomposition procedure for understanding the sources of cost differences across firms. The analysis is based on expenditures in eight plans in seven large firms and considers differences in average annual individual expenditures, treatment rates, treatment intensity, and "prices" of treatment based on three years of pooled claims data. The firms were selected for this initial study partly because they offer only one plan to each employee. One of the firms has two plans, but each plan serves a different employee group. Using one-plan firms helps ensure that the cost differences observed are not confounded by the self-selection of employees into plans. It is possible that employees select firms based on health plan characteristics or, conversely, that the aggregate characteristics of firm employees influence the health plans offered. Because our firms have thousands of employees and dependents, however, a 
large number of employees would have to select the firm primarily for health insurance reasons rather than other firm characteristics for such an effect to be substantial.

\section{Summary Data}

Each person who reports medical spending in a year is assigned to a "predominant diagnosis group." This group is the one to which the largest share of an enrollee's expenditures can be allocated. There are thirty such groups listed in table 1.1. These groups include outpatient and "residual," which includes expenditures not assigned to any of the identified groups. Persons who are assigned to the lung cancer group, for example, have spent a substantial amount for the treatment of lung cancer. They are likely to have had some expenditures reported in other diagnosis groups for care that may or may not be related to lung cancer.

The diagnosis groups are listed in table 1.1 by the average cost of treatment-over all eight plans-given that diagnosis group. The average treatment cost ranges from $\$ 34,736$ for lung cancer to $\$ 1,110$ for the outpatient predominant diagnosis group. The average diagnosis rate is shown in the first column of the table. Almost 92 percent of enrollees are in the outpatient group. The diagnosis rate for the other groups is typically well under 1 in 100 and often as low as 1 in 1,000. Approximately 2 percent of enrollees are in the residual group. The diagnosis rate times the treatment cost given diagnosis gives the average cost per enrollee, shown in the third column of the table. Finally, the proportion of total expenditures accounted for by each diagnosis group is shown in the last column. About 48 percent of cost is accounted for by the 92 percent of employees in the outpatient group and about 18 percent is accounted for by the approximately 2 percent who are in the residual category. The remaining 34 percent is accounted for by the 6 percent of persons in the other diagnostic groups. We will see that differences across firms in both diagnosis rates and treatment cost given diagnosis account for large differences in average expenditure. Indeed, both may contribute to higher or lower costs in the same firm, or one may increase and the other may decrease cost in the same firm.

The key elements of cost difference are the diagnosis rate and treatment cost given diagnosis. The diagnosis rates in each plan are shown in table 1.2. The treatment costs are shown in table 1.3. Consider 
Table 1.1

Summary; mean cost by diagnosis

\begin{tabular}{|c|c|c|c|c|}
\hline & $\begin{array}{l}\text { Mean rate } \\
\text { of } \\
\text { diagnosis }\end{array}$ & $\begin{array}{l}\text { Mean cost } \\
\text { given } \\
\text { diagnosis }\end{array}$ & $\begin{array}{l}\text { Mean } \\
\text { expenditure } \\
\text { per enrollee }\end{array}$ & $\begin{array}{l}\text { Percentage } \\
\text { of total } \\
\text { expenditure }\end{array}$ \\
\hline Lung cancer & 0.00027 & 34,736 & 9.36 & 0.0044 \\
\hline Colorectal cancer & 0.00031 & 27,819 & 8.71 & 0.0041 \\
\hline AMI & 0.00117 & 26,651 & 31.29 & 0.0147 \\
\hline $\begin{array}{l}\text { Chronic obstructive } \\
\text { pulmonary disease }\end{array}$ & 0.00056 & 25,179 & 14.17 & 0.0067 \\
\hline $\begin{array}{l}\text { Stroke: occlusive and } \\
\text { hemorrhagic }\end{array}$ & 0.00077 & 24,901 & 19.19 & 0.0090 \\
\hline Congenital & 0.00034 & 23,131 & 7.78 & 0.0037 \\
\hline Neonatal care & 0.00091 & 22,917 & 20.83 & 0.0098 \\
\hline Heart failure & 0.00072 & 22,826 & 16.40 & 0.0077 \\
\hline Arthritis & 0.00087 & 22,788 & 19.82 & 0.0093 \\
\hline Prostate cancer & 0.00029 & 20,000 & 5.87 & 0.0028 \\
\hline IHD, chest pain & 0.00558 & 18,270 & 102.02 & 0.0480 \\
\hline Residual & 0.02225 & 17,656 & 392.93 & 0.1847 \\
\hline Breast cancer & 0.00032 & 17,594 & 5.67 & 0.0027 \\
\hline $\begin{array}{l}\text { Psychotic/major affective } \\
\text { psychosis }\end{array}$ & 0.00413 & 16,759 & 69.28 & 0.0326 \\
\hline Back/spine disorders & 0.00257 & 15,509 & 39.92 & 0.0188 \\
\hline Neurotic & 0.00144 & 15,050 & 21.73 & 0.0102 \\
\hline Injury/trauma & 0.00401 & 13,964 & 55.94 & 0.0263 \\
\hline Diabetes & 0.00081 & 13,228 & 10.70 & 0.0050 \\
\hline Gallbladder disease & 0.00213 & 11,442 & 24.34 & 0.0114 \\
\hline Substance abuse & 0.00262 & 10,944 & 28.70 & 0.0135 \\
\hline Respiratory infection & 0.00299 & 9,872 & 29.48 & 0.0139 \\
\hline Benign female pelvic, etc. & 0.00469 & 9,383 & 44.02 & 0.0207 \\
\hline Appendicitis & 0.00104 & 8,123 & 8.49 & 0.0040 \\
\hline $\mathrm{BPH} /$ urinary obstruction & 0.00145 & 7,972 & 11.57 & 0.0054 \\
\hline Asthma & 0.00126 & 7,792 & 9.84 & 0.0046 \\
\hline Abnormal pregnancy & 0.00393 & 7,406 & 29.09 & 0.0137 \\
\hline Abnormal childbirth & 0.00653 & 6,234 & 40.73 & 0.0191 \\
\hline Normal childbirth, mother & 0.00279 & 5,350 & 14.94 & 0.0070 \\
\hline Normal childbirth, child & 0.00475 & 3,152 & 14.97 & 0.0070 \\
\hline Outpatient & 0.91847 & 1,110 & $1,019.55$ & 0.4793 \\
\hline All & 1.00000 & & $2,127.33$ & 1.0000 \\
\hline
\end{tabular}


substance abuse, for example. The diagnosis rate varies from a low of 5 in 10,000 enrollees to a high of 60 in 10,000. The treatment cost varies from a high of $\$ 17,377$ to a low of $\$ 7,117$.

Beginning with the data in tables 1.2 and 1.3 (including the raw data that underlie the means), we want to decompose the average cost differences across plans, which range from a low of $\$ 1,645$ to a high of $\$ 2,484$. There are three reasons for cost differences: (1) differences in the demographic attributes-age and gender-of enrollees, (2) differences in the illnesses that are treated-the diagnosis rate, and (3) differences in the cost of treating illnesses. Our goal is to attribute observed cost differences to these three sources. A particular complication is that treatment cost differences across plans may vary substantially by diagnosis, and we would like to know which diagnoses account for differences in treatment cost. A firm with low treatment cost for one diagnosis may have high treatment cost for another diagnosis; thus, it is important to consider possible interactions across diagnoses in addition to the interaction between diagnoses and treatment cost.

\section{The Decomposition of Cost Differences}

We begin with the eight plans described above. As explained, the members of each plan are divided into thirty "predominant" diagnosis categories, defined by the diagnosis group in which the largest share of a member's expenditure in a given year occurred. The data can be thought of as arranged in two 30 by 8 matrices, as shown in tables 1.1 and 1.2. The first matrix reports the proportion of enrollees in each plan who are in each of the diagnosis groups. The second matrix reports the average cost of treating patients in each of the diagnosis groups.

We want to know why the costs in one plan differ from the average cost. Consider diagnosis $\mathrm{k}$ : what accounts for the difference in expenditure for treating patients in this diagnosis in plan $i$, compared to the average expenditure for treating patients with diagnosis $k$ ? The diagnosis could be pregnancy, or cancer, or outpatient care, for example. The relative cost depends on two factors: (1) the proportion of enrollees treated for diagnosis $\mathrm{k}$ (the rate) and (2) the cost of their treatment given that diagnosis. Both the rate and the cost will depend on the demographic mix (age and gender) of persons in plan i compared to the average mix across all plans. First we control for demographic mix and then consider expenditure differences, adjusted for demographic mix. The decomposition steps follow: 


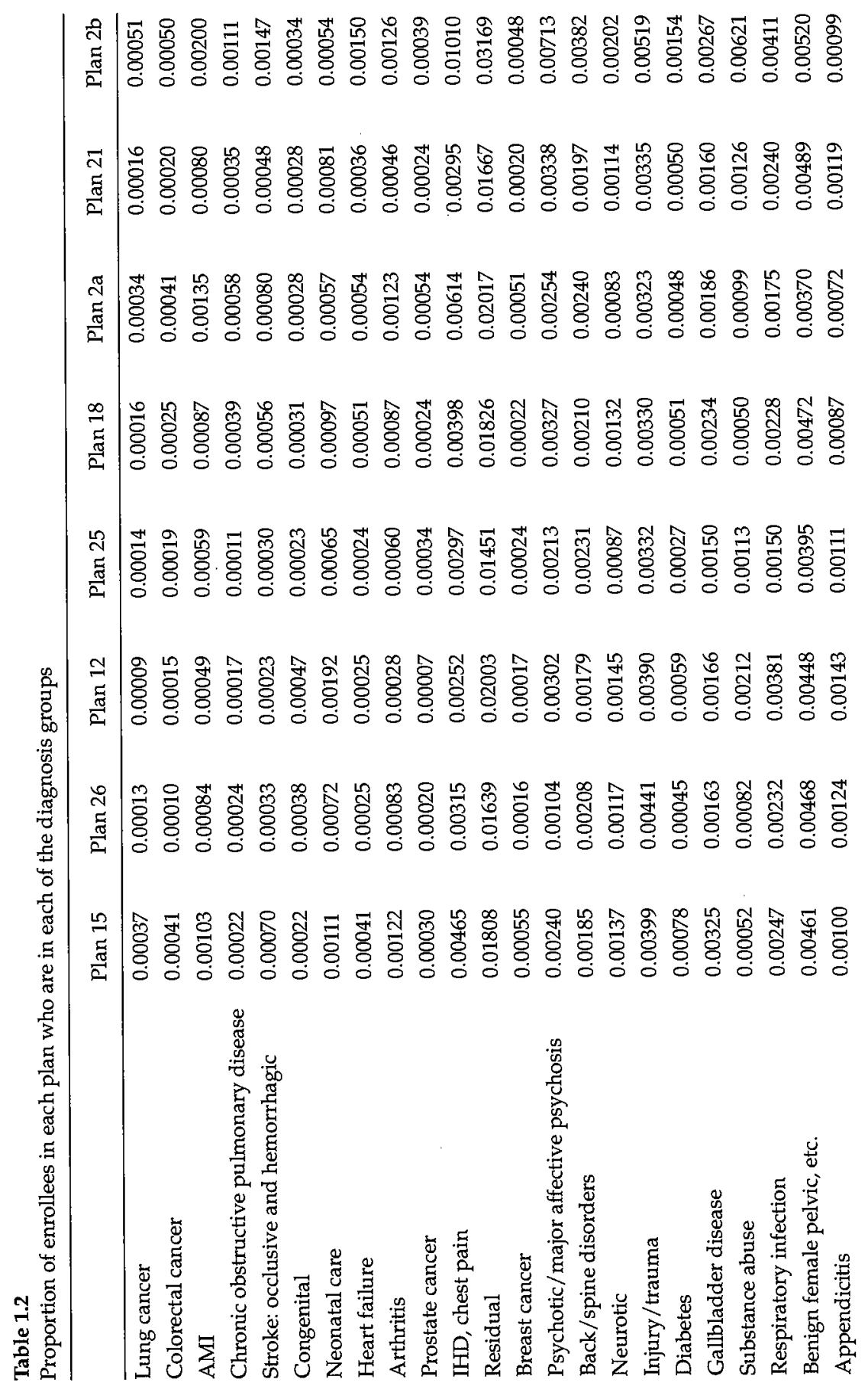




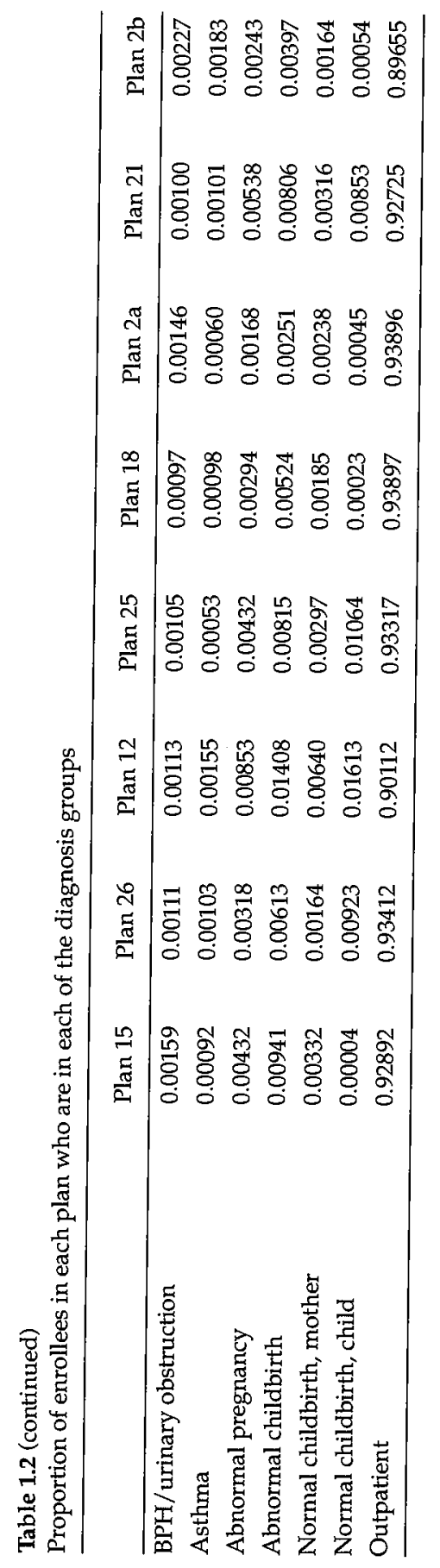




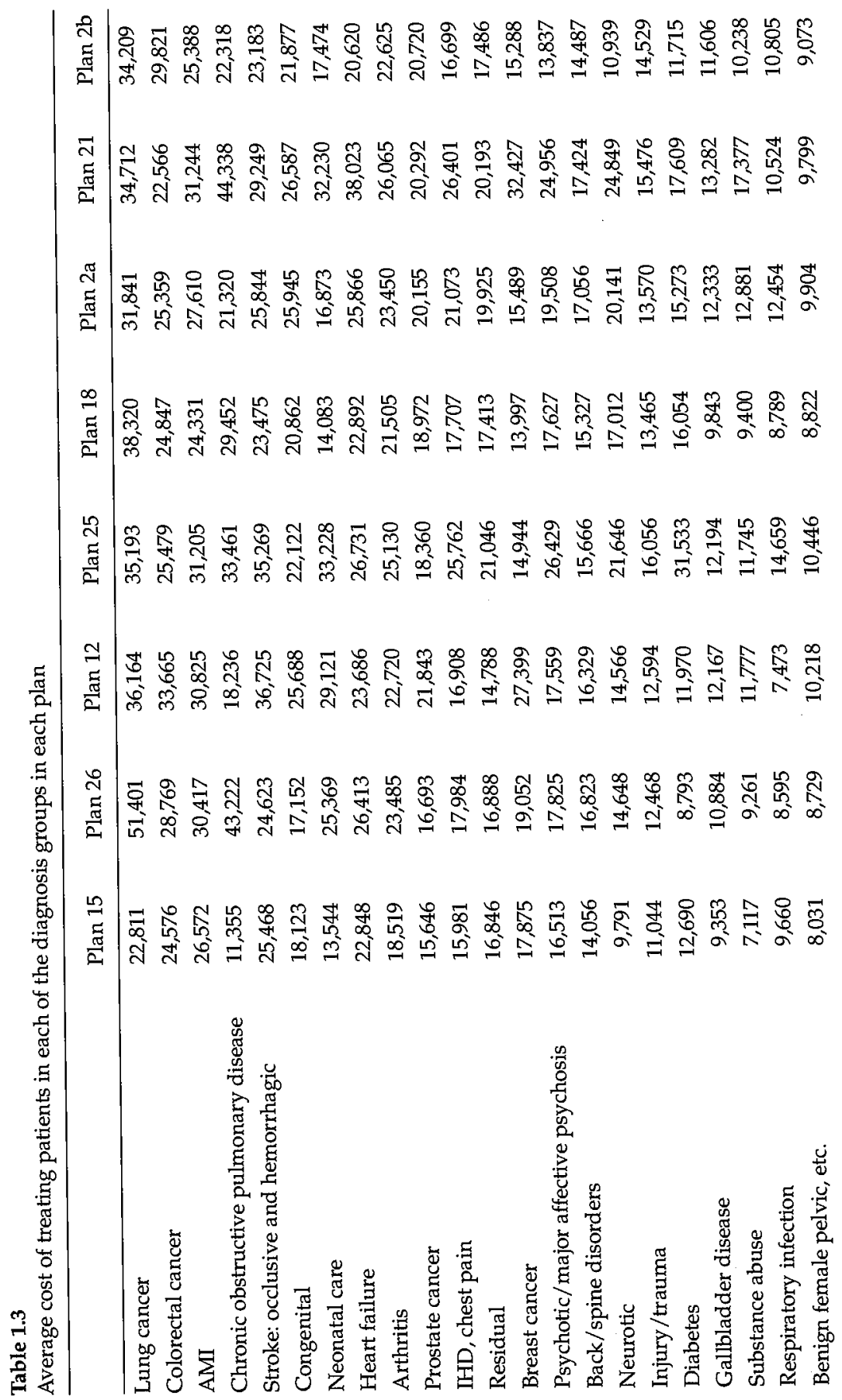




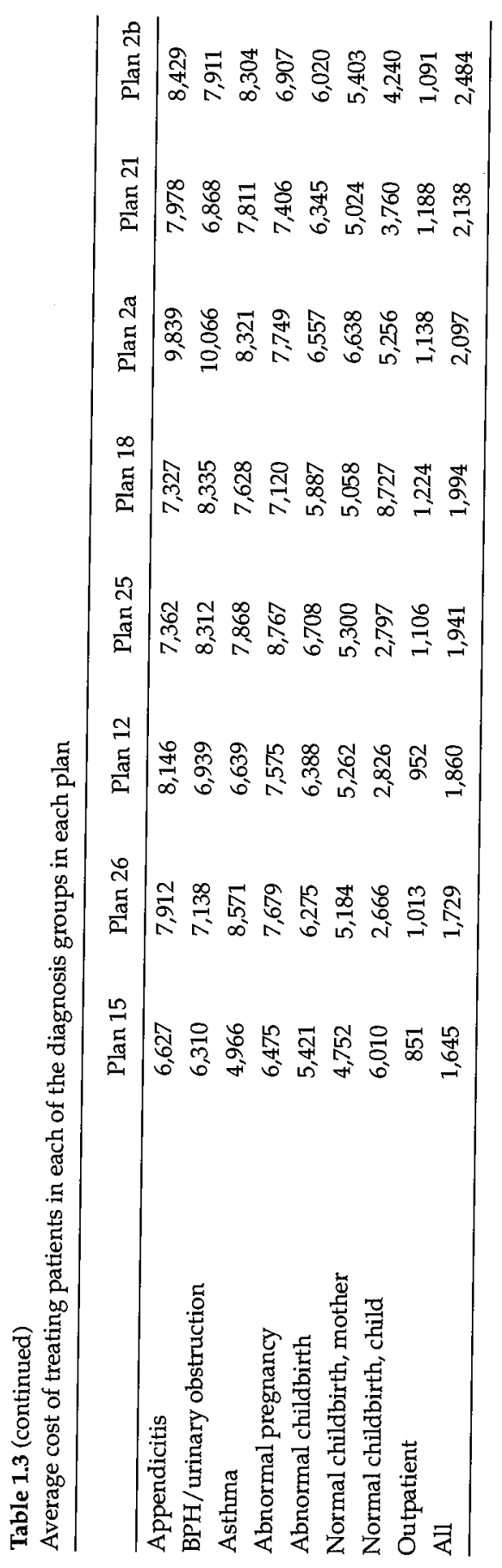


First, how much of the rate and the cost for each treatment can be attributed to the demographic mix of plan members?

Total demographic effect is decomposed into:

Effect of demographic mix on the rate of diagnosis

Effect of demographic mix on treatment cost given diagnosis

Interaction

Second, the cost differences that remain after demographic adjustment are broken down as follows.

Total remaining effect is decomposed into:

Difference due to diagnosis rate

Difference due to treatment cost given diagnosis

Interaction

Third, the interaction between the first and second components.

In discussing the results below, we will ignore the third component and, for the most part, the other interaction terms as well. These terms ensure that the decomposition components add to total expenditure, but they are small. The technical details of the decomposition are presented and discussed in Eichner, McClellan, and Wise (1999).

\section{Results for the Eight Plans}

The decomposition results for the eight plans are explained in some detail here. The presentation is primarily graphical, but we begin with table 1.4 because it presents the complete decomposition succinctly. The eight plans are ordered from left to right by mean expenditure per enrollee, which is shown in the thirteenth row of the table. The average cost over all plans is $\$ 2,127$ and is shown in the twelfth row. The difference between the plan mean and the overall average is shown in the last row of the table. This difference is decomposed into the elements shown in the rows above. The difference is divided into three main components that correspond to the sources identified above: demographic adjustment, demographic adjusted difference, and the interaction between the two. Each of the first two main components is decomposed into three "mix effects": rate, cost, and interaction. The third main component is composed of only two terms. The sum of the sources of cost difference is equal to the difference between the plan cost and the overall average across all plans, or the sum of the sources of cost difference plus the overall mean equals the plan mean. 


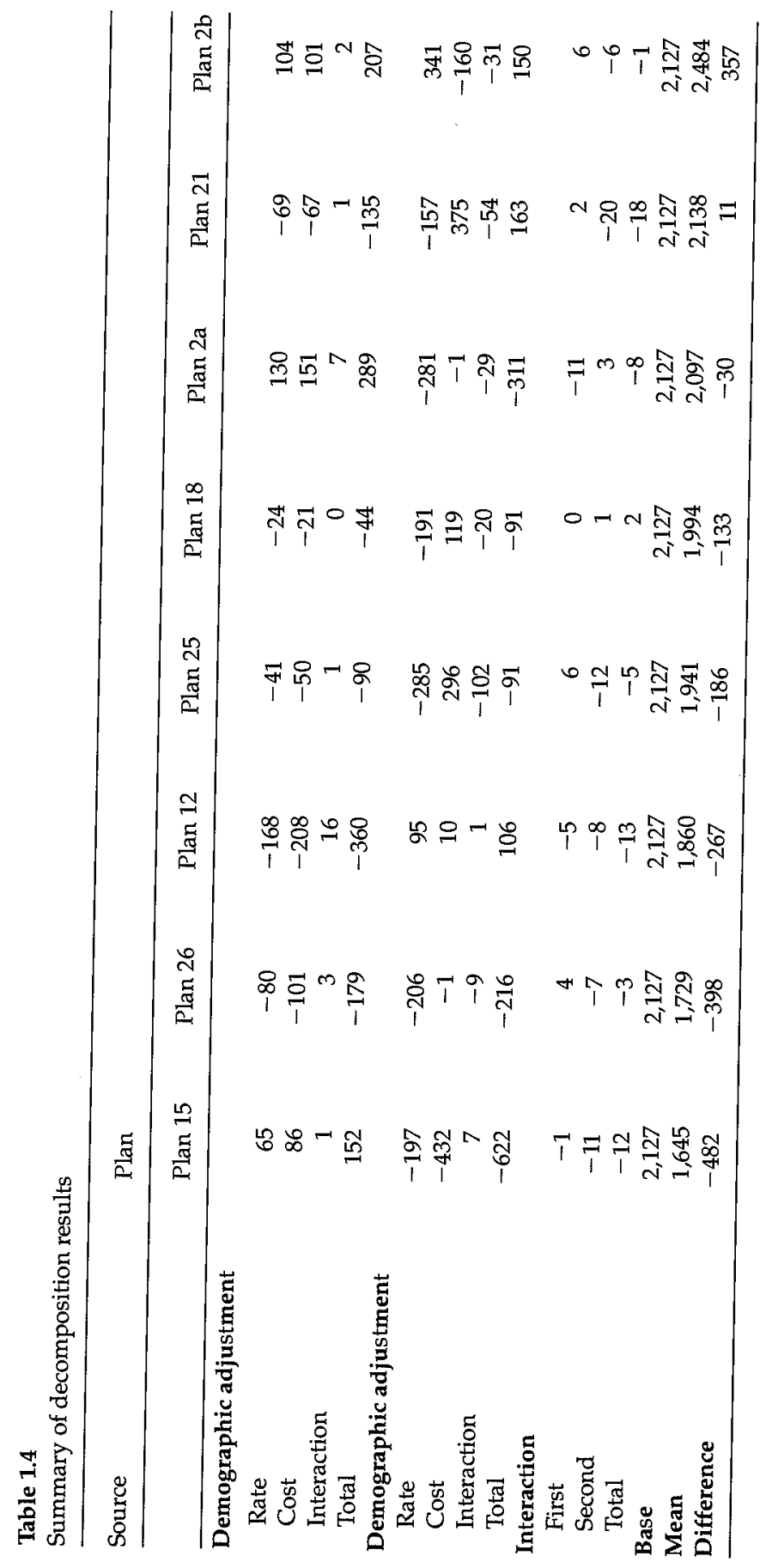


For example, consider plan 15 . The expenditure per enrollee in plan 15 is $\$ 482$ less than the average. The demographic adjustment effect is $\$ 152$, which means that the demographic mix in plan 15 increases the cost-relative to the other plans-by $\$ 152$. But the increase in expenditure due to demographic mix is offset by a lower demographically adjusted expenditure. The demographic adjusted expenditure effect is $-\$ 622$, which means that after adjusting for demographic mix expenditure per enrollee in plan 15 is $\$ 622$ less than the average. The sum of the demographic adjustment (\$152) plus the expenditure effect $(-\$ 622)$ plus the small interaction term $(-\$ 12)$ is equal to the expenditure difference of $-\$ 482$.

Each of these three components is further decomposed into rate and cost effects (and a small interaction effect). For example, the demographic mix in plan 15 increases the treatment rate in higher cost diagnoses, which increases expenditures relative to the average by $\$ 65$. And the demographic mix also increases the cost of treatment, which increases expenditures relative to the average by $\$ 86$. The sum of the rate effect ( $\$ 65)$, the cost effect $(\$ 86)$, and the small interaction effect $(\$ 1)$ is equal to the total demographic adjustment (\$152). The demographic adjusted expenditure effect is also decomposed into a rate effect, a cost effect, and an interaction. For plan 15, the rate effect is -\$197, which means that, after controlling for demographic mix, the diagnosis rate is concentrated in lower cost diagnoses, relative to the average. The treatment cost effect is $-\$ 432$, which means that treatment cost is lower than average. The sum of the rate effect $(-\$ 197)$, the cost effect $(-\$ 432)$, and the small interaction effect (\$7) equals the total demographic adjusted expenditure effect $(-\$ 622)$.

The elements of the decomposition explained above pertain to all of the thirty diagnoses combined, and we often refer to them as mix effects. To understand the contribution of differences from the average for particular diseases, however, it may be useful to consider the components for a single diagnosis. Suppose that we are considering expenditure for a given diagnosis $\mathrm{k}$ in a given plan $\mathrm{i}$, after controlling for the demographic mix in the plan. Figure 1.1 shows the procedure. The square defined by solid lines represents the average expenditure-across all firms-of treating persons in diagnosis group $\mathrm{k}$. The deviation of the cost in plan $i$ from the average over all plans is represented by the three components of the outer box: (1) the rate effect, represented by the top slice, which is the added expenditure due to the greater treatment rate of diagnosis $\mathrm{k}$ in firm $\mathrm{i}$, holding the expenditure 


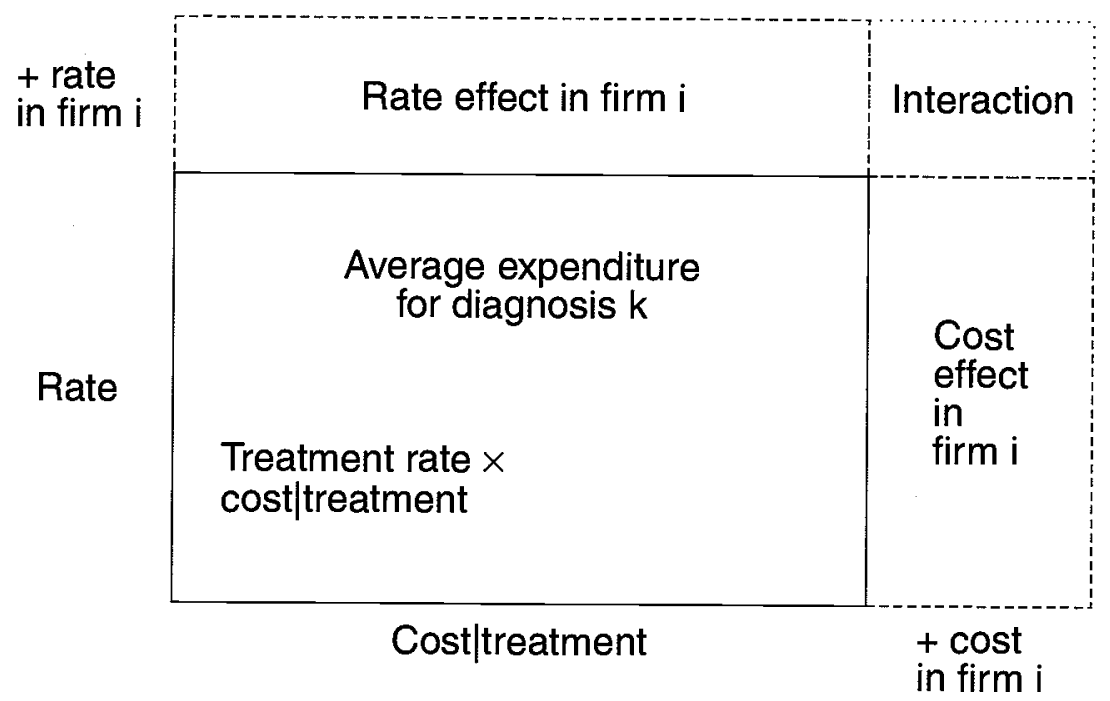

Figure 1.1

Diagnosis $k$ treatment cost in firm $i$

at the base level; (2) the cost effect, represented by the righthand slice, which is due to the higher cost of treating diagnosis $\mathrm{k}$ in firm $\mathrm{i}$, holding the treatment rate at the base level; and (3) the product of the rate difference times the expenditure difference, the interaction term, which is represented by the small square at the upper right.

We explain the details of the deconstruction with the aid of several figures. To begin, the total expenditure differences across the eight plans, taken from the last row of figure 1.7, are graphed in figure 1.2. The range is from $-\$ 482$ to $+\$ 356$, a difference of $\$ 838$. These expenditure differences are graphed in figure 1.3 together with the expenditure differences after adjusting for differences in demographic mix across firms. For example, relative to the average, expenditure in plan 15 is even lower after the demographic adjustment. The demographic mix in plan 15 increases expenditure relative to the average. Overall, the demographic adjustments are quite substantial, from $-\$ 360$ to $+\$ 289$, a range of $\$ 649$. Nonetheless, even after adjusting for demographic mix, the difference in expenditure is still very large, from $-\$ 642$ in plan 15 to $\$ 163$ in plan 21 , a range of $\$ 772$. Thus, the range in demographic adjusted expenditures is not much less than the $\$ 838$ range in unadjusted expenditures. But the demographic adjustment changes the order of expenditures by plan. For example, adjusted expenditures are much 


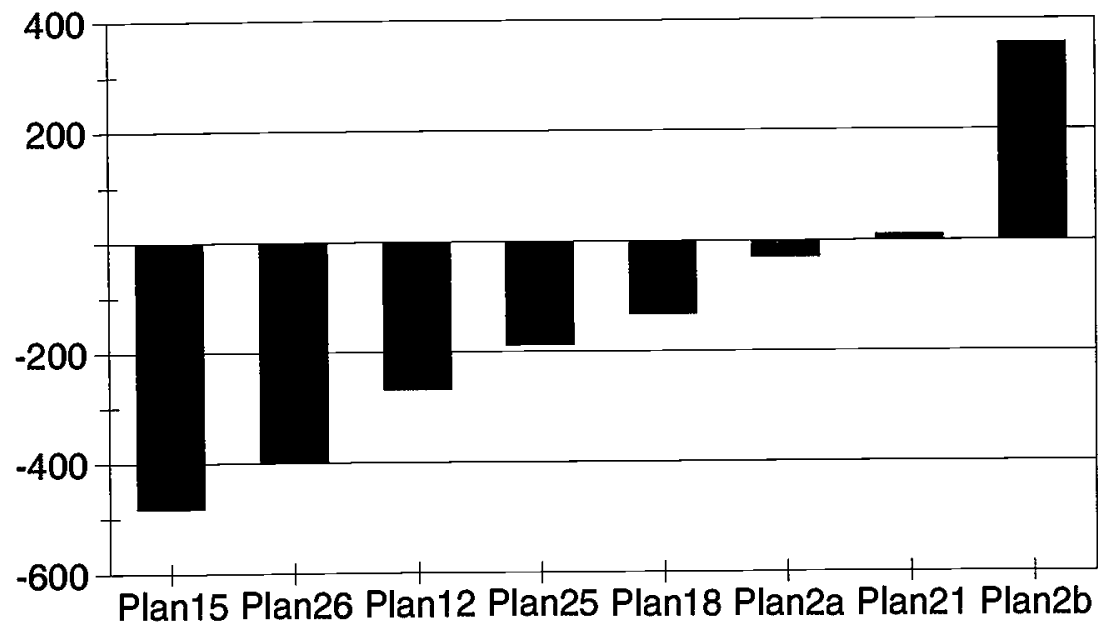

\section{Total Difference}

Figure 1.2

Total expenditure difference before demographic adjustment

higher than unadjusted expenditures in plan 12 , but in plan $2 \mathrm{a}$, adjusted expenditures are much lower than the unadjusted expenditures.

Perhaps the most important results are shown in figure 1.4, which describes the decomposition of the difference in expenditure that remains after the demographic adjustment. Suppose that all rates and treatment costs have been adjusted for demographic mix. What accounts for the remaining difference? Refer again to figure 1.4. There are three sources of the difference between the expenditure in a plan and the average expenditure over all plans: (1) the difference in diagnosis rate, holding the treatment cost at the average; (2) the difference in treatment cost, holding the diagnosis rate at the average; and (3) the interaction of the first two. The first bar in figure 1.4 reproduces the difference in expenditure adjusted for the demographic mix shown in figure 1.3.

The next three bars show how the difference holding the demographic mix constant is divided into the three sources. The second bar shows the difference that can be attributed to the diagnosis rate mix. A bar extending upward, like that for plan $2 b$, for example, indicates that the rate mix in plan $2 b$ is concentrated in higher cost diagnoses, relative to the average over all plans. The difference attributable to rate mix 


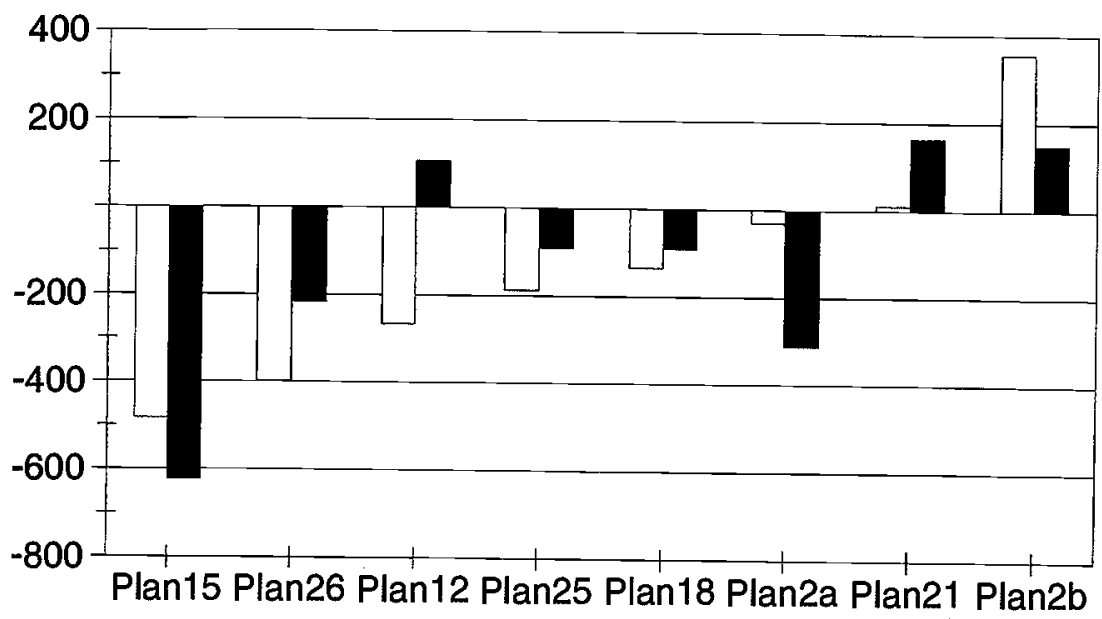

Total Difference

Adjusted Difference

Figure 1.3

Total expenditure difference before and after demographic adjustment

goes from a low of $-\$ 285$ in plan 25 to a high of $\$ 341$ in plan $2 b$, a range of $\$ 626$.

The next bar indicates the difference that can be attributed to differences in treatment cost. Again, a bar extending upward indicates that treatment cost, given diagnosis, is higher than the average. After adjusting for demographic mix, the range in cost that can be attributed to treatment cost differences alone is still very large-from a low of $-\$ 432$ in plan 15 to a high of $\$ 375$ in plan 21 , a range of $\$ 807$.

The last bar shows the interaction between diagnosis rate deviations from the average rate and treatment cost deviations from the average. A bar extending downward indicates a negative correlation between the two. This component is typically negative, although there are two very small positive values (plan 15 and plan 12). Consider plan 25 , for example. The diagnosis rate mix favors diagnoses having low average treatment cost. But in this firm, treatment costs tend to be higher than the average. Looking across the plans, the negative interaction components indicate that lower diagnosis rates are typically associated with higher treatment costs, although the effect is small. The firm, on average, treats fewer enrollees for high-cost diagnoses, but treatment costs for those who are treated are higher than the average treatment cost. 


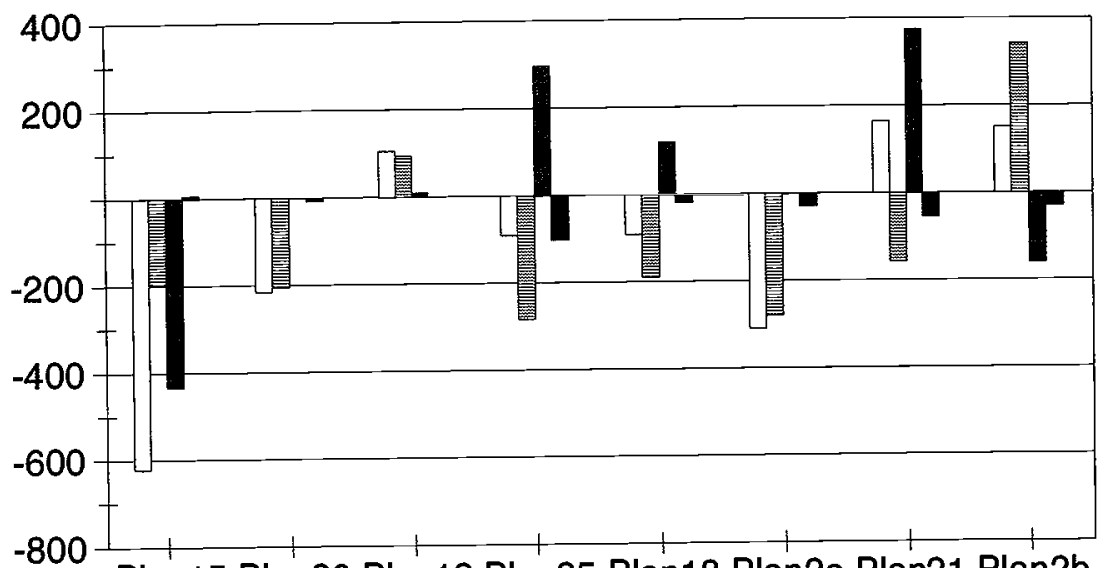

Plan15 Plan26 Plan12 Plan25 Plan18 Plan2a Plan21 Plan2b

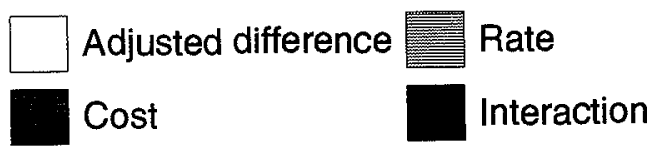

Figure 1.4

Decomposition of adjusted expenditure difference

Unlike the demographic mix that changes the rate mix and the cost mix in the same direction, the demographically adjusted rate and cost mix seem to follow no particular pattern across firms. (The within-firm interaction between rate and cost tends to be negative, as emphasized above.) Figure 1.5 presents the same data as figure 1.4, but in figure 1.5 the plans are ordered by the total adjusted expenditure difference. it is easy to see in this figure that there doesn't seem to be a particular relationship between the component attributable to the rate mix and the portion attributable to the cost mix. For the three plans with the lowest adjusted cost, no component is positive (with the exception of the small interaction term for plan 2a), but for the other plans, the rate and cost mix components seem to follow no particular pattern. Plans $2 a$ and $2 b$ are in the same firm, and adjusted costs differ by $\$ 461$. (The unadjusted cost difference is $\$ 387$.) The difference is primarily due to the rate mix, which accounts for a difference of $\$ 622$. The plan 2a rate mix is concentrated in low-cost diagnoses, and the plan $2 \mathrm{~b}$ rate mix is concentrated in high-cost diagnoses. This difference attributable to rate mix is partially offset by the cost difference: costs are in fact $\$ 159$ lower in plan $2 b$ than they are in plan 2a. The small differences that can be attributed to the interaction between the demographic adjustment and the adjusted 

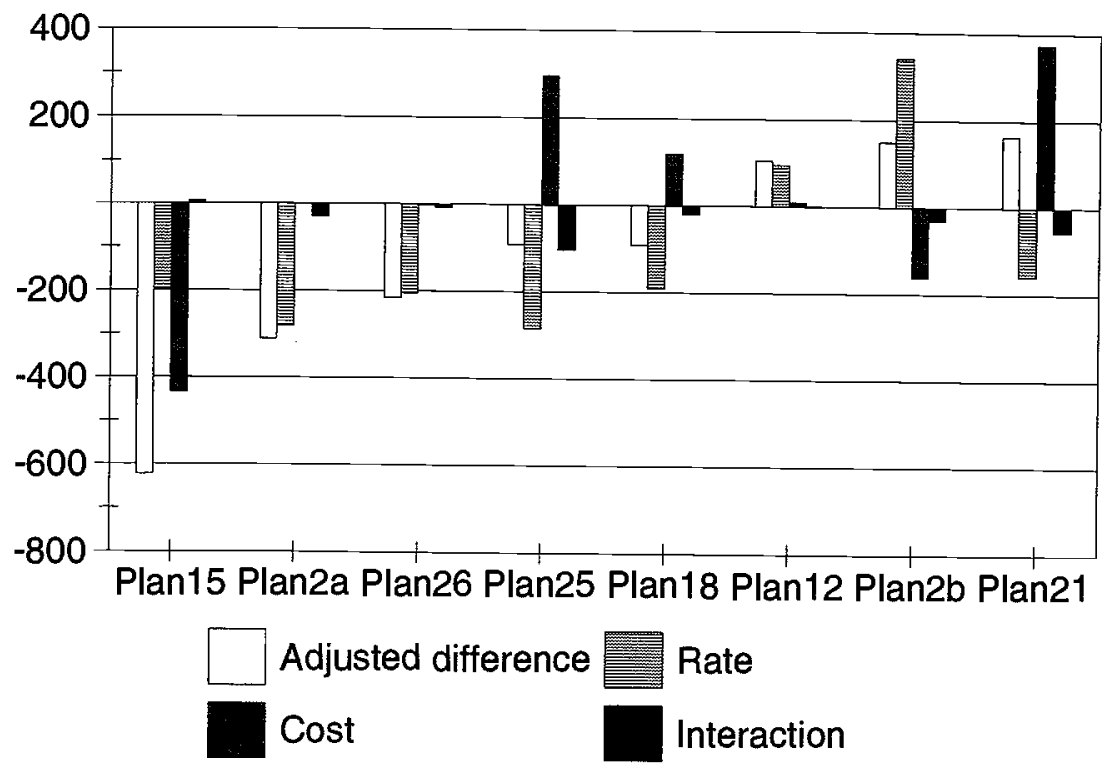

Figure 1.5

Decomposition of adjusted cost difference

cost differences are not shown graphically but can be seen in table 1.5, which summarizes the results thus far. It shows first the range in unadjusted expenditures, then the range in demographic mix adjustments, the range in adjusted expenditures, and finally the range in adjusted treatment costs.

Perhaps the most noticeable feature of these results is that the range in demographic adjusted expenditures accounted for by the treatment cost mix (\$807) is almost as wide as the unadjusted range in expenditures (\$838). Even though the effects of demographic mix are large, with the difference between the lowest and highest adjustments equal to $\$ 649$, remaining differences in treatment cost are still very large. Differences in cost due to the different mixes of illness that are treated also accounts for large differences in cost (\$626) once demographic mix is controlled for.

Once the decomposition has been set out in this way, more detailed comparisons can be made. For example, is there a relationship between the "severity" of the diagnosis and differences in treatment cost across plans? Figure 1.6 suggests that there is little relationship. It shows the range in cost for each of the thirty diagnoses divided by the average treatment cost for the diagnosis. There is essentially no relationship. Of 


\section{Table 1.5}

Range in differences by source

\begin{tabular}{ll}
\hline Source & Range \\
\hline Unadjusted expenditures & $\$ 838$ \\
Demographic mix: total & $\$ 649$ \\
Demographic adjusted expenditures: total & $\$ 772$ \\
$\quad$ Rate mix & $\$ 626$ \\
Treatment cost mix & $\$ 807$ \\
\hline
\end{tabular}

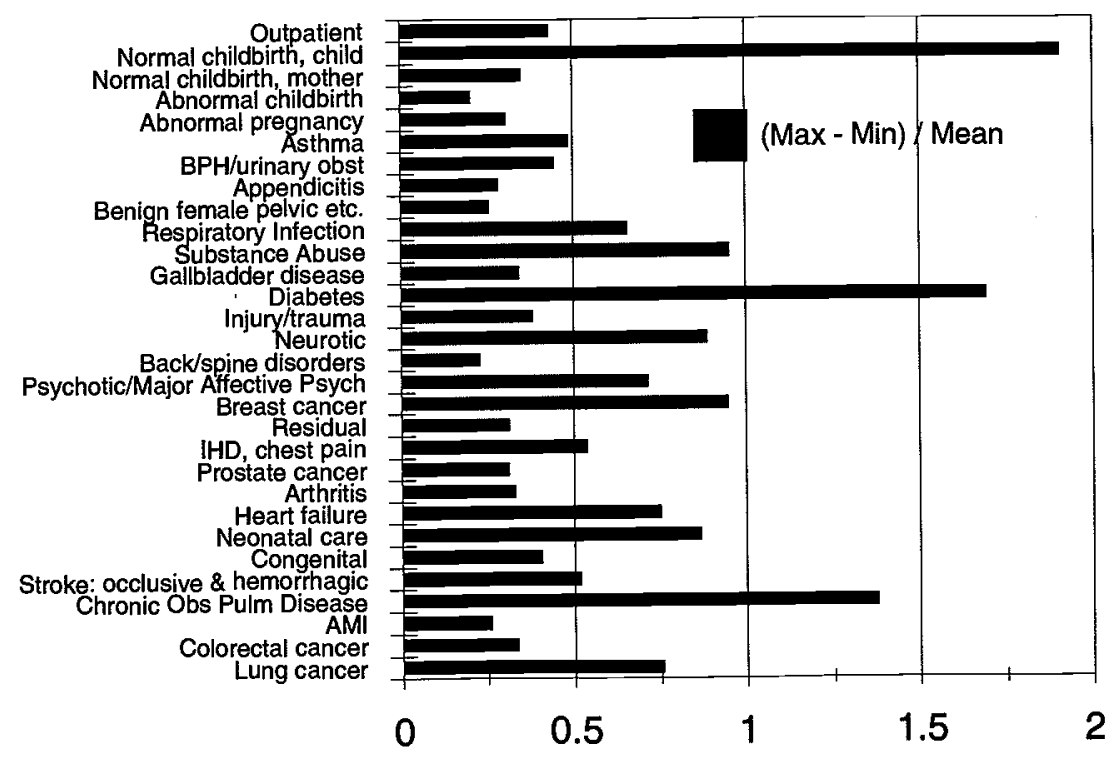

Figure 1.6

Adjusted cost range versus mean 


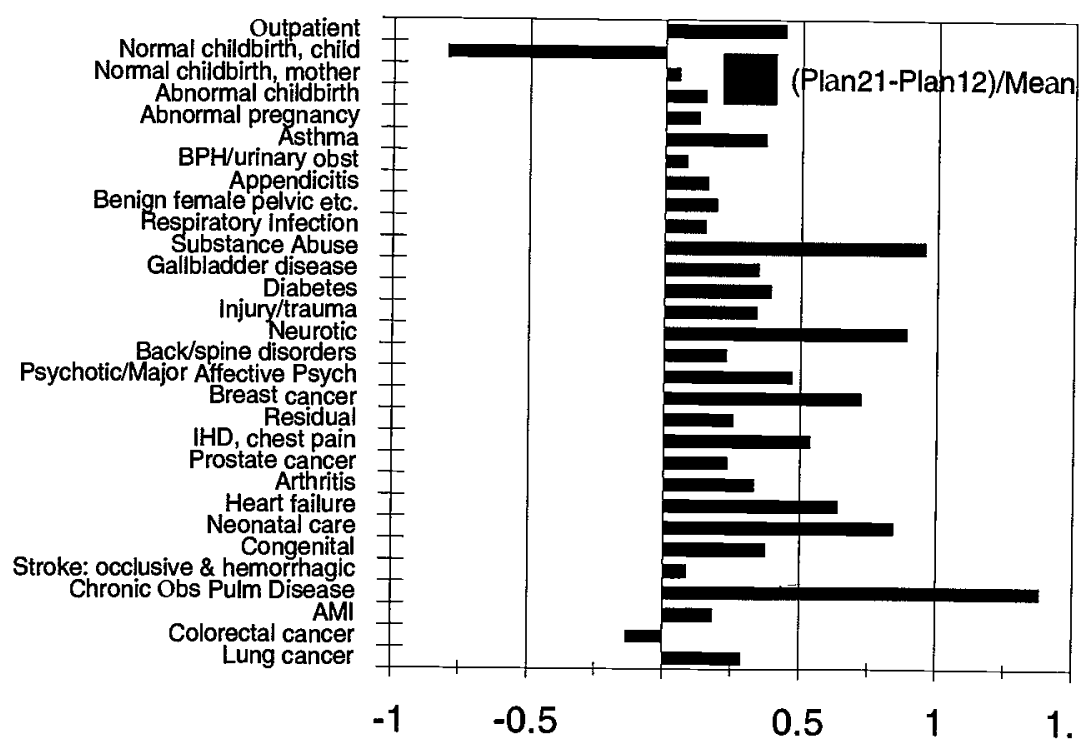

Figure 1.7

Adjusted cost difference versus mean

course, the range in dollar differences increases with average treatment cost, but the differences normalized by average cost do not.

Figure 1.7 compares the differences between treatment costs by diagnosis in the highest and lowest treatment cost plans (demographically adjusted). Plan 21 has the highest treatment cost and plan 15 has the lowest. One important feature of this figure is that, in all but two diagnoses-which are ordered by average treatment cost-the cost is higher in the high-cost plan 21 than in the low-cost plan 15. The other feature is that the cost difference normalized by average treatment cost is unrelated to the average cost of treatment. Thus, the treatment cost is higher for almost all diagnoses in the high-cost plan, and the relative difference is unrelated to average treatment intensity.

While treatment costs are consistently higher in the high-cost plan, Figure 1.8 shows no evident pattern in the treatment rates in these two plans. Similar deconstruction calculations based on plans from multiplan firms suggest that the rate as well as the treatment cost may vary systematically by plan, with the treatment cost negatively related to the diagnosis rate. This result is not consistent with a selection effect, in which unfavorable selection would be expected to result both in 


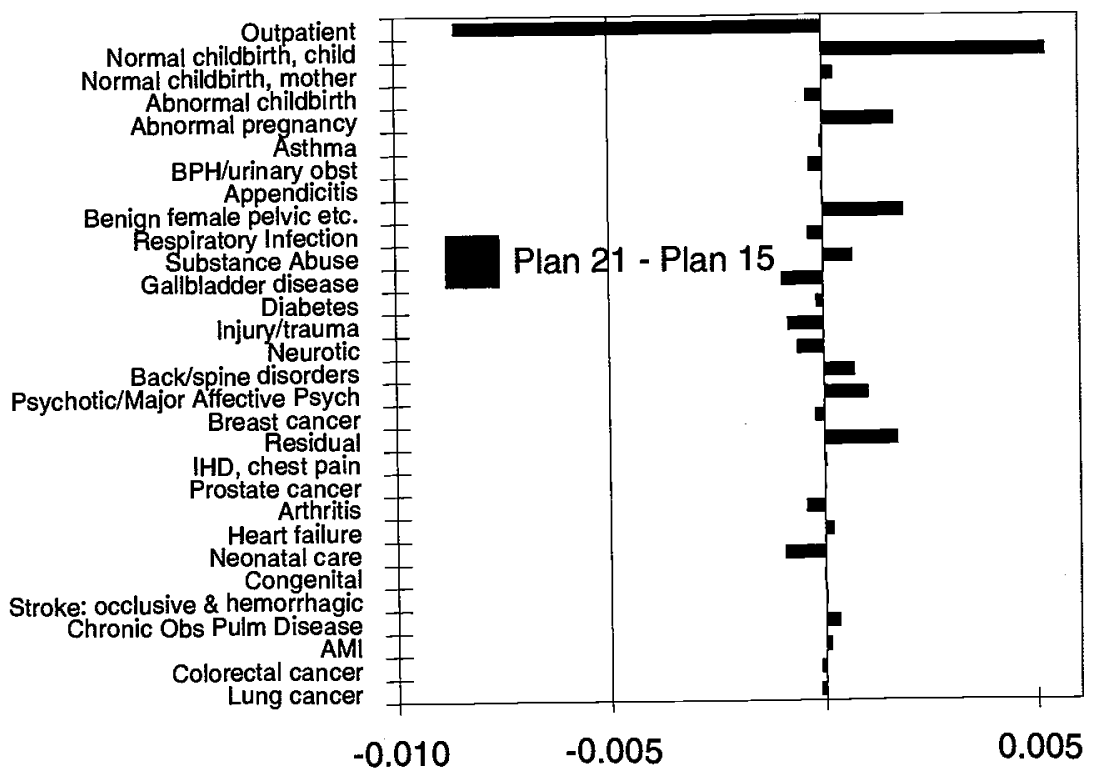

Figure 1.8

Adjusted rate difference

higher diagnosis rates and higher treatment intensity. The result is consistent with more aggressive treatment of a disease, resulting in higher diagnosis rates and higher total costs, which may mean more intensive treatment of "marginal" patients who would not be treated as intensively in other plans.

Figures 1.9 and 1.10 show the cost and rate differences by diagnosis for the two plans-2a and $2 b-$ that are in the same firm. Demographically adjusted costs are $\$ 159$ higher in plan $2 a$ than in plan $2 b$. Figure 1.9 shows that plan 2a cost is greater in all but seven of the thirty diagnosis groups. But again there is little relationship between the normalized difference and the average treatment cost, although the figure suggests that the differences may be somewhat lower for high-treatment-cost diagnoses. On the other hand, the rate mix in plan 2a is more concentrated in low-cost diagnoses than it is in plan $2 b$. Indeed the rate in the three lowest cost diagnoses is higher in plan 2a but lower in all but two of the remaining diagnoses. Thus, these data suggest that the differences in plan provisions yield higher treatment costs in plan 2a but fewer treatments for high cost diagnoses. On balance, the lower treatment rate outweighs the higher costs. 


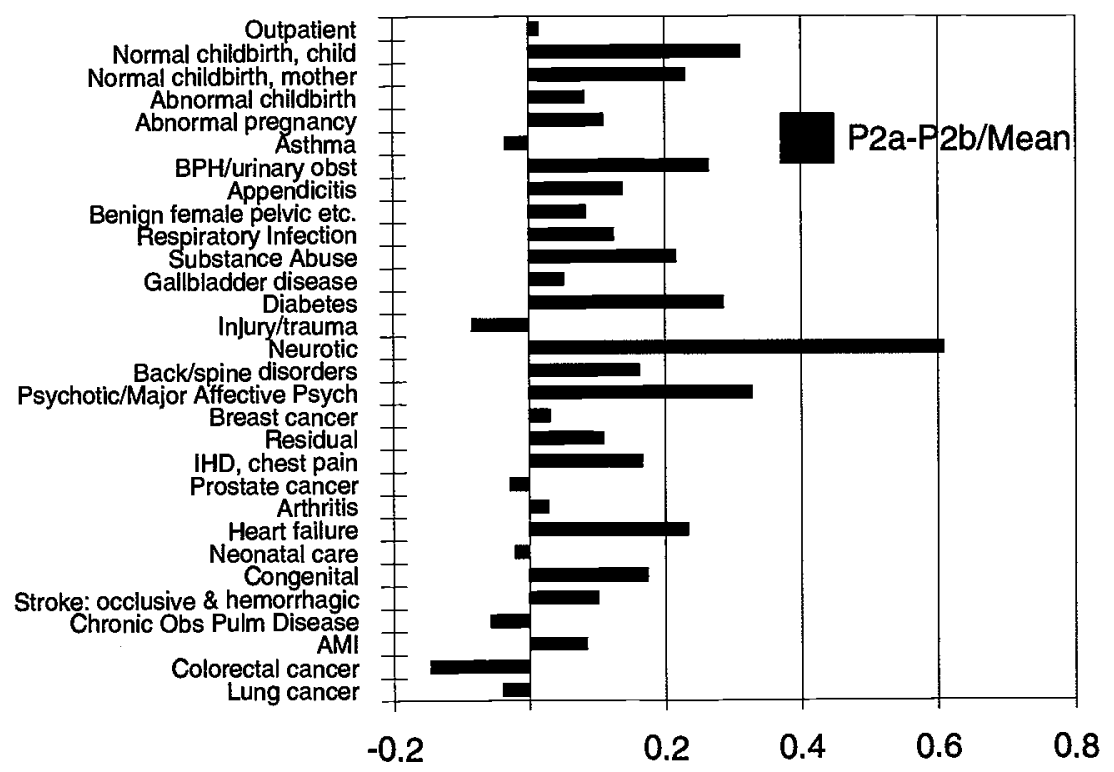

Figure 1.9

Adjusted cost difference

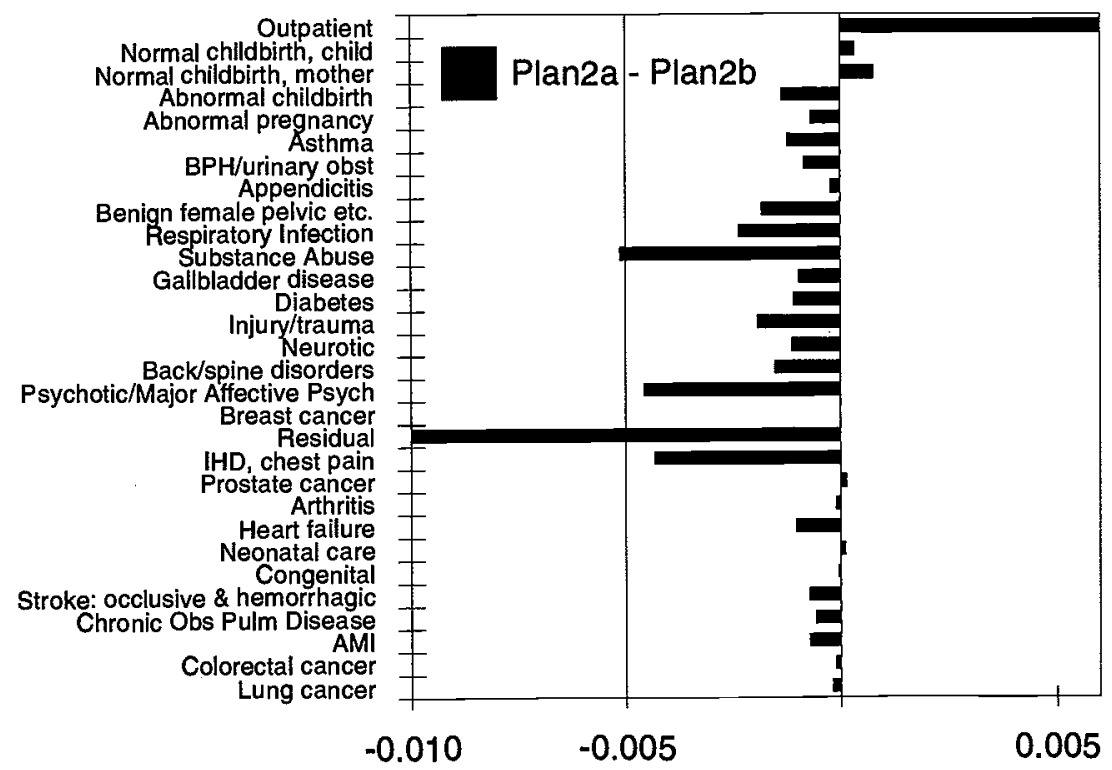

Figure 1.10

Adjusted rate difference 


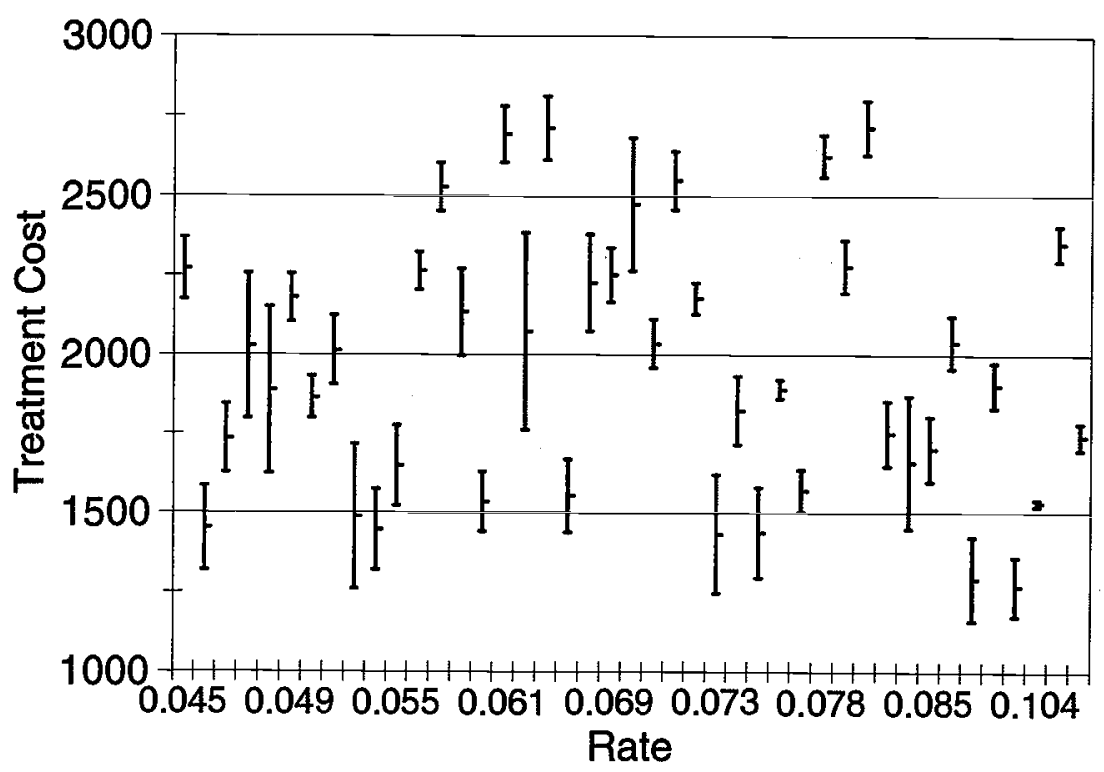

Figure 1.11

Mental health plus substance abuse

\section{Variation Across Many Plans for Two Diagnoses}

For some diagnoses, we have begun to calculate rate and treatment cost-adjusted for demographic mix-for several plans. In our terms, expenditure is given by treatment rate times cost given treatment. As the systematic decomposition suggests, both the rate of treatment and cost given treatment contribute greatly to expenditure differences across firms. We consider two illustrations: mental illness and substance abuse, and pregnancy (childbirth). Treatment for mental illness and substance abuse combined accounts for about 5.6 percent of health care expenditures in the eight plans discussed above, not counting outpatient treatment.

Figure 1.11 shows treatment cost by treatment rate for mental illness and substance abuse in forty-three plans. (In this and subsequent figures, the "high-low" bands around the treatment cost estimates represent 95 percent confidence intervals for these estimates.) Both the rate of treatment across plans and treatment cost vary by a factor of more than two. Thus, both contribute to the variation in expenditure across firms. The same is true for substance abuse and mental illness considered separately. The data for mental illness alone are shown in Figure 


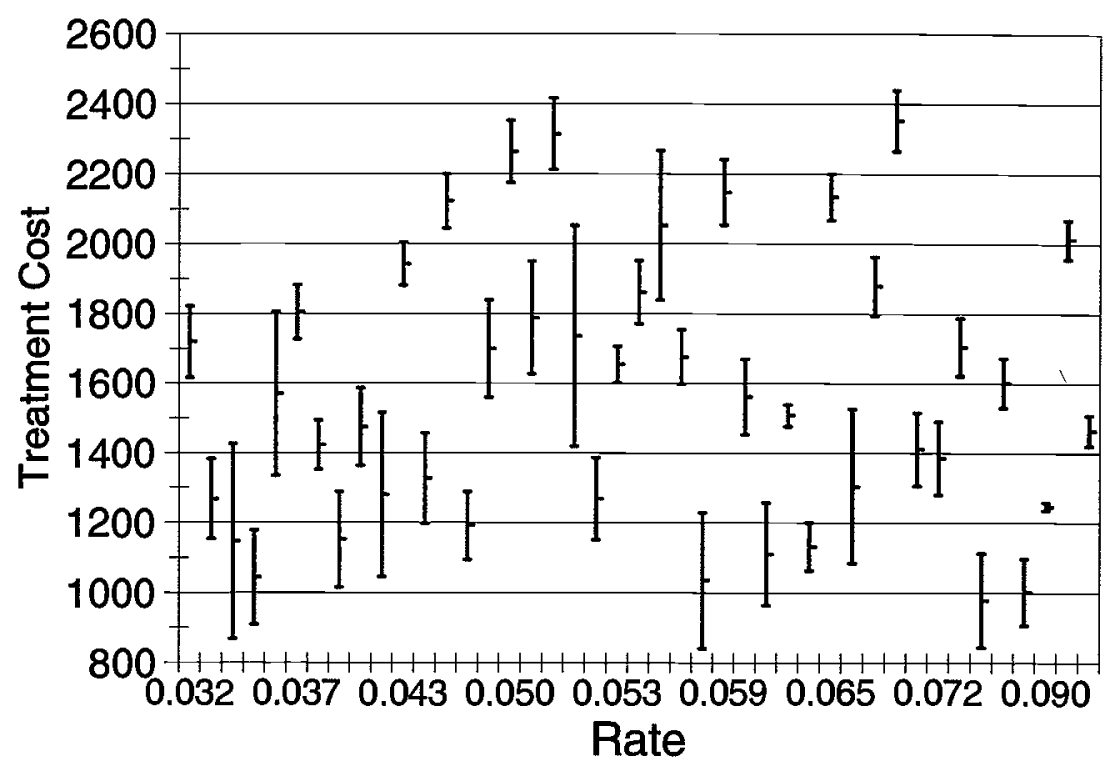

Figure 1.12

Mental health

1.12. In this case, the treatment rate varies by a factor of more than three and treatment cost varies by a factor of about two and a half. The intensity (mode) of treatment is of course an important determinant of cost. Figures 1.13 and 1.14 show differences in the rate and cost of outpatient (less intensive) versus inpatient (more intensive) treatments. In both cases there is large variation in both the rate and cost of treatment.

Pregnancy (including childbirth) provides another illustration. In the eight plans discussed above, pregnancy accounts for about 4.7 percent of health care expenditures. Both the rate of pregnancy and the cost of delivery contribute to the wide variation in expenditure. Figure 1.15 shows treatment cost for pregnancy by the rate of pregnancy. The rate varies by a factor of about two and the rate for treatment cost varies by about one and a half. An important determinant of cost is the intensity of treatment for delivery, in particular vaginal delivery (less intensive) versus cesarean (more intensive). Figures 1.16 and 1.17 show that the rate and cost for these alternative levels of treatment intensity vary substantially across plans. (In this case, the rate is shown as the percentage of all deliveries that are vaginal and cesarian.)

Although not shown here, similar figures show wide variation in AMI rate and treatment cost. And no matter what the mode of 


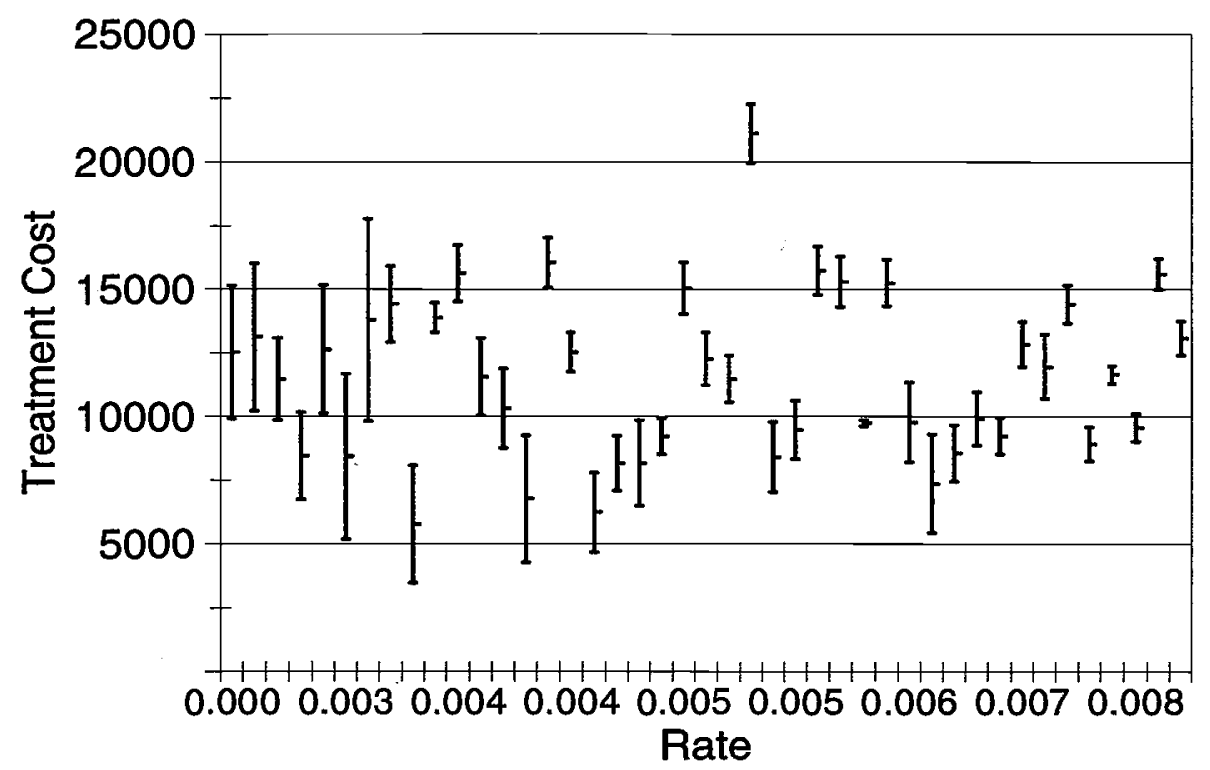

Figure 1.13

Mental health-inpatient

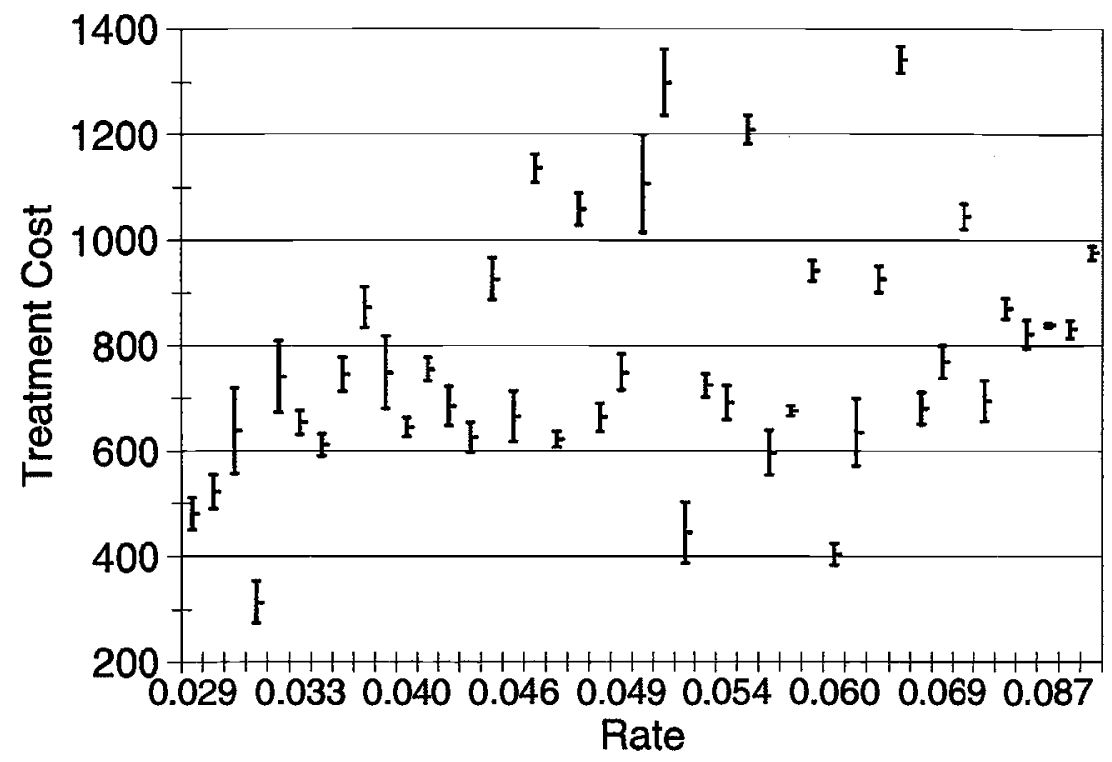

Figure 1.14

Mental health-outpatient 


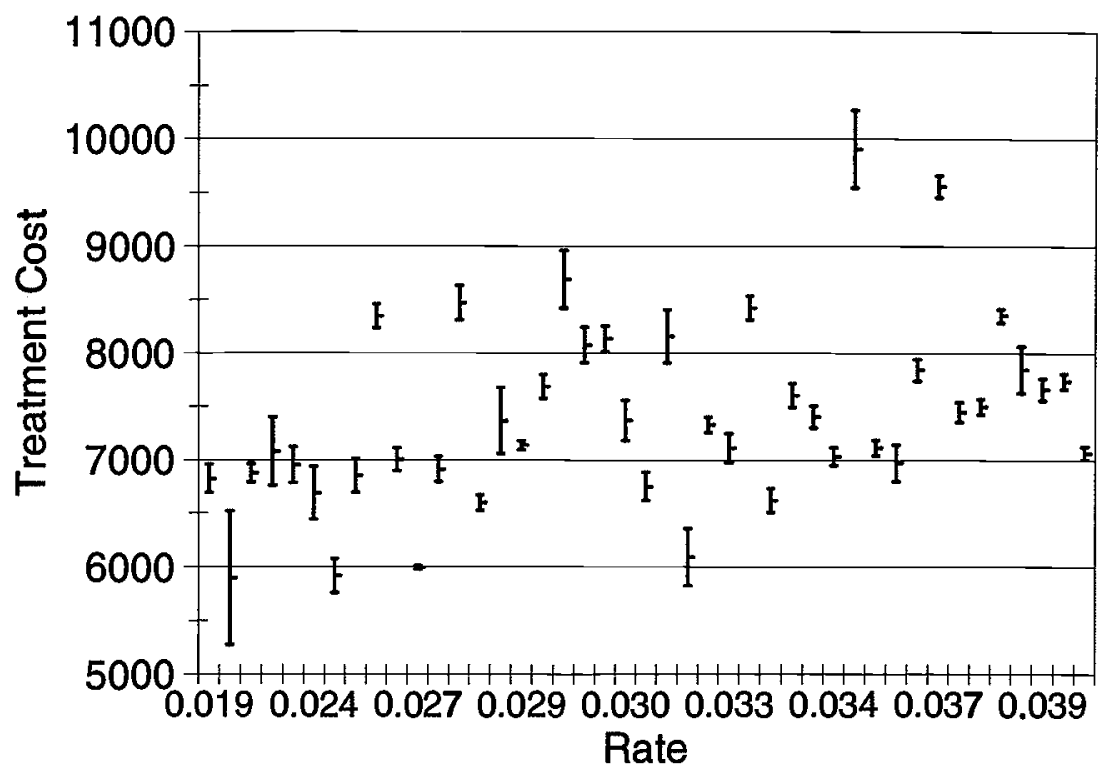

Figure 1.15

All pregnancies (deliveries)

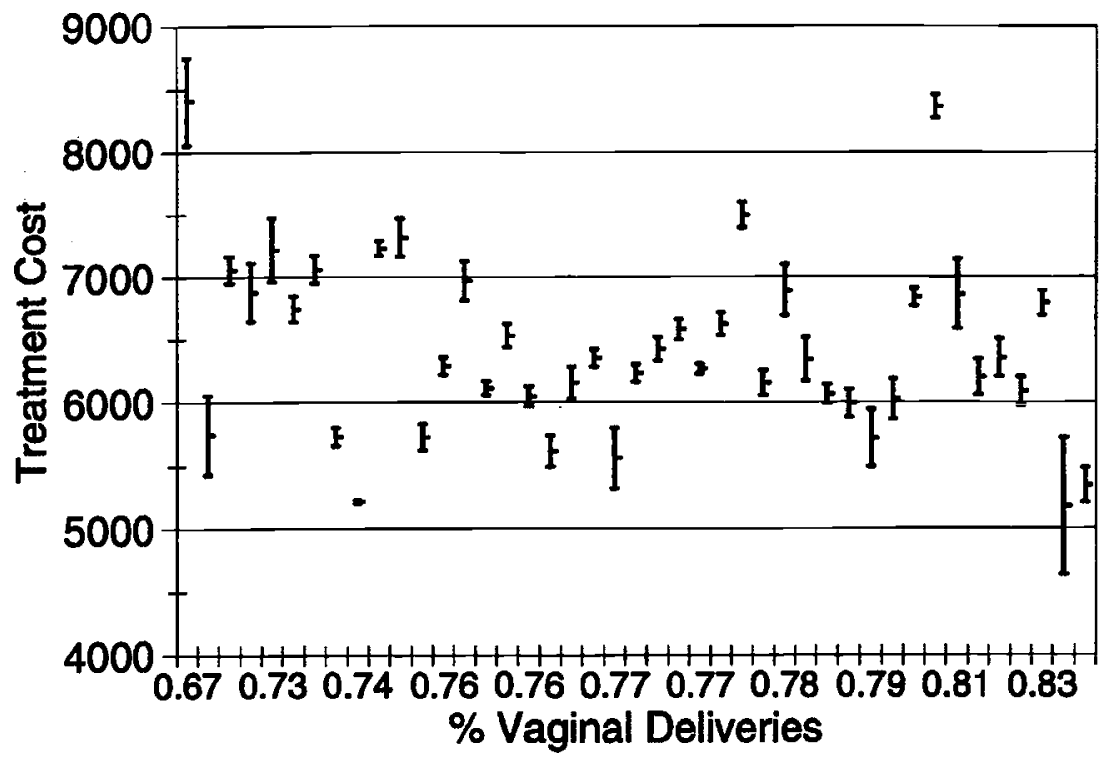

Figure 1.16

Vaginal deliveries 


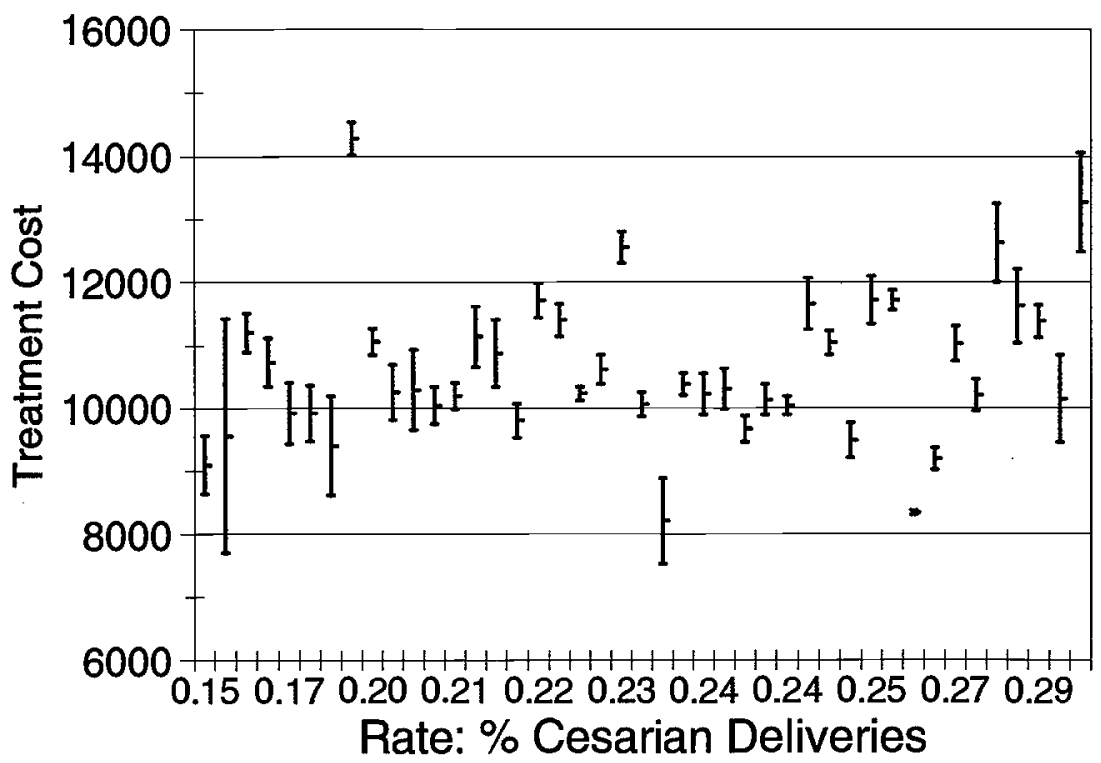

Figure 1.17

Cesarean deliveries

treatment, both the rate and the treatment cost vary substantially across plans.

These illustrations make clear that expenditure variation across all plans is determined both by the rate of treatment and by treatment cost. Even for given modes of treatment, like cesarian versus vaginal delivery, both the rate and the treatment cost vary greatly across plans.

\section{Summary and Discussion}

To understand better the sources of cost differences in health care expenditures across firms, we have developed a method to decompose expenditure differences across firms into their component parts. While an important goal is to illustrate the method, the substantive results also seem striking. We have documented large differences in health care spending across the eight firms included in our analysis. Our decomposition does not say why the differences exist, but it does indicate which differences must be explained if differences in health care costs are to be understood. The results show large differences across plans in 
both treatment cost and in the rate of treatment for various diagnoses, even after the demographic mix effects have been removed. The findings suggest that both differences in treatment intensity as well as diagnosis mix may be affected by differences in plan provisions. Both differences could be attributed to plan incentives. Recall that this analysis is based on one-plan firms. Selection effects within firms are not confounded with incentive effects, as is typically the case when employees are offered a menu of plans from which to choose. Although these results do not adjust for regional differences in health care cost, they are consistent with cost differences attributed in part to regional differences in treatment practice and the price of health care. We know, however, that differences in treatment cost like those shown in figure 1.7 exist between firms in the same geographic locations. Indeed there is a large difference between the costs in plans $2 a$ and $2 b$, which are in the same geographic locations. In this case, the cost difference can be attributed primarily to differences in diagnosis rate mix.

Some of these descriptive findings on the relationship between demographic characteristics, disease treatment rates, and expenditures associated with particular diseases can be translated almost directly into implications for policy and additional research. For example, we can quantify the average effects of each of these factors on private health care spending and identify the "high-variation" groups that account for the bulk of differences in expenditures across employers. By using these methods with panel data, we can also quantify the main sources of changes in health care expenditures and the high-variation components of expenditure growth across firms. When combined with a breakdown of trends in the major components of health costs, the decomposition will permit assessment of the determinants of future medical cost increases under the current system. The findings can also be used to assess the effects of trends in the demographic composition of firm workforces. Finally, we can assess the effects of changes in insurance coverage, like opening Medicare to persons 55 to 64 . We plan to extend these analytic methods to the much larger number of firms participating in our study.

\section{Note}

We thank the National Institute on Aging and the Hoover Institution (Wise) for financial support. 


\section{References}

Eichner, M. J., "Incentives, price expectations, and medical expenditures: An analysis of claims under employer-provided health insurance." New York: Columbia University, Graduate School of Business, mimeograph 1997.

Eichner, M., M. McClellan, and D. Wise, "Health Expenditures Persistence and the Feasibility of Medical Savings Accounts," in Tax Policy and the Economy 11, MIT Press, 1997.

Eichner, M., M. McClellan, and D. Wise, "Insurance or Self-Insurance? Variation, Persistence, and Individual Health Accounts," in D. Wise, ed., Inquiries in the Economics of Aging, University of Chicago Press, 1998.

Eichner, M., M. McClellan, and D. Wise, "The Sources of Cost Difference in Health Insurance Plans: A Decomposition Analysis," presented at the Economics of Aging conference in Carefree, Arizona, May 1999. University of Chicago Press, in press.

McClellan, M., and D. Wise, "Where the Money Goes: Medical Expenditures in a Large Corporation," NBER Working Paper \#5294, October 1995, and in A. Garber and S. Ogura, eds., Issues in Health Care in the United States and Japan, University of Chicago Press, in press. 